\title{
Exílio e perspectivismo interamericano. Estudo e fontes para uma definição das relações literárias entre Argentina e Brasil no século XIX*
}

\author{
Exile and Inter-American Perspectivism, Study and Sources for a Definition of 19th \\ Century Argentine and Brazilian Literary Relations
}

\section{Davidson de Oliveira Diniz}

\author{
Pós-doutorando no Departamento de Sociologia da Universidade de São Paulo \\ Bolsista Fapesp \\ davis.diniz@gmail.com
}

\begin{abstract}
Resumo: Este artigo se ocupa de uma série de fontes primárias referentes às relações intelectuais, políticas e literárias entre a Argentina e o Brasil em contexto do romantismo e de formação das literaturas nacionais. Analisa assim o processo de exílio de escritores argentinos em Montevideo, Pelotas e, especialmente, Rio de Janeiro, considerando documentos arquivados no Setor de Manuscritos da Fundação Biblioteca Nacional do Brasil. Busca-se nesse sentido conceituar a prática do que frente a tais eventos viemos a denominar perspectivismo interamericano, isto é, uma reorientação do comparatismo de origem europeia em latitudes americanas frente ao problema da autonomização literária emergente do entrecruzamento de poéticas nacionais argentina e brasileira a partir do deslocamento de escritores rio-platenses em trânsito ou exilados na cidade do Rio de Janeiro entre os anos 1843 e 1952.
\end{abstract}

Palavras Chaves: Literatura Argentina; Literatura Brasileira; Exílio.

\begin{abstract}
This article deals with a series of primary sources concerning intellectual, political and literary relations between Argentina and Brazil, specifically related to romanticism and the formation of national literature. It analyses the exile of Argentine authors in Montevideo, Pelotas and, in particular, Rio de Janeiro, with special focus on the archival documents found in the Manuscripts Section of Brazil's National Library Foundation. It thus sets out to conceptualize a practice which, faced with aforementioned events, we have denominated "Inter-American perspectivism", that is, a reorientation of comparativism away from its European origins to American latitudes, in light of the problem of the emergent autonomization of literature which in turn is the result of the crossing of Argentine and Brazilian national poetics through the displacement of Rioplatense writers, in-transit or exiled, in the city of Rio de Janeiro between 1843 and 1952.
\end{abstract}

Keywords: Argentine Literature; Brazilian literature; Exile.

\footnotetext{
* "Pós-doutorando com financiamento FAPESP no de processo 2016/26250-1. Esta pesquisa também recebeu financiamento do programa PNAP-R da Fundação Biblioteca Nacional (2015 e 2016)."
} 


\section{A sociogênese do perspectivismo interamericanista}

A sociogênese do perspectivismo interamericanista entre a Argentina e o Brasil se organiza entre dois eixos argumentativos característicos do começo das relações literárias bilaterais entre os referidos países. Pelo que toca ao meio argentino, é importante notar a reinvindicação de um vinculo político intercontinental, nomeado "revolução americana", isto é, a adoção da república como sistema político e da democracia como sistema de governo, imperativos que se acreditavam necessários para as emancipações políticas e poéticas do continente. Tal demanda irrompeu com a determinação do exílio imposto pelo governo de Juan Manoel de Rosas (1835-1852) à chamada Geração de 1837, bem como a outros agrupamentos políticos argentinos.

Durante a condição de trânsito interamericano, argentinas e argentinos expatriados passariam a cobrar adesão brasileira à causa republicana originária do Partido Unitário (1816-1862) das Províncias Unidas do Rio da Prata, sediado em Buenos Aires, frente ideológica com cujas propostas compactuava a maioria dos escritores e escritoras refugiados na cidade do Rio de Janeiro ou outras praças brasileiras, como foi o caso de Pelotas e Porto Alegre. A configuração monárquica do Brasil Império fazia com que o grupo de exilados argentinos na corte de Pedro II se sentisse de antemão ameaçado na sua reivindicação republicana.

Assim, o tom das primeiras mediações não veio senão justamente de uma apressada preconcepção, rendendo, por parte dos letrados argentinos, a prévia condenação dos brasileiros, declarada ou sub-repticiamente acusados de não terem rompido com as raízes coloniais, tomados, por isso mesmo, como indiferentes à "revolução americana", uma vez distantes do republicanismo ao se deixarem submeter a um governado monarquista. Daí que o momento inicial de sociação política e literária mais não revelaria senão a antiga face de um velho antagonismo interamericano de raízes ibéricas, repaginado pela configuração de um cenário político divergente entre o republicanismo hispano-americano e a monarquia imperial brasileira. Em certa medida, tal antagonismo espelharia a greta primordial imposta pelo Tratado de Tordesilhas (1494), sendo progressivamente desfeita à medida que se construía o imperativo da autonomização literária entre ambos os países, conforme veremos ao longo deste texto.

Para que alteração significativa ocorresse nas primeiras impressões bilaterais, viria a ser necessária a aclimatação tropical dos degredados argentinos, sobretudo 
daqueles que se encontravam na cidade imperial, lugar em que perceberiam algo distinto da velha imagem exótica do paraíso tropical brasileiro. Tal conjuntura os levaria a ressignificar a imagem de um Brasil só-natureza, vale dizer, a descobrir um país - ou assim pelo menos qualificar a sua capital imperial - dotado de processo civilizatório, fato que serviria de exemplo para o embate unitário contra a "barbárie" federalista do sistema autoritário imposto por Rosas (cf. AMANTE, 2010).

Pela parte letrada brasileira, que singular e curiosamente se anteciparia à mediação promovida pelo corpo intelectual argentino acolhido no Brasil a partir da década de 1840, colocou-se certa trama argumentativa que veio pela primeira vez a sugerir um viés de sincronismo poético não mais determinado pela clássica derivação entre as literaturas americanas e as europeias. Enquanto a ressignificação americana da imagem-Brasil partiria de um grupo de escritores exilados residentes ou em deslocamento pela cidade imperial, de um grupo, portanto, vinculado à instituição política argentina republicana, a filiação unitária da Geração de 1837, a ressignificação interamericana da imagem-Argentina, no que respeita ao Brasil, partiu, primeira e aparentemente, de uma ação isolada, ou seja, individual, e ilhada, isto é, erradicada no território brasileiro, atividade devida às ações do polígrafo Joaquim Norberto Souza Silva. Porém numa segunda camada da sedimentação, conforme veremos nos desdobramentos subsequentes, o vínculo bilateral, como atividade desempenhada pela parte brasileira, ressonâncias seriam encontradas não exclusivamente no campo letrado, de onde o gesto precursor de Joaquim Norberto veio a irradiar os inícios das sociabilidades. Isso porque do lado brasileiro atuaria em paralelo um corpo político e diplomático já conformado profissionalmente, protagonizando as relações exteriores e práticas diplomáticas imperiais com a Confederação Argentina e a Republica Oriental do Uruguai, enquanto os escritores argentinos se reconfigurariam politicamente, no sentido restritivo do termo, somente após a queda de Rosas (1851/1852), mediante os cargos que lhes seriam atribuídos durante a presidência do general Justo José de Urquiza (1801-1870). Trata-se especificamente das ações de Hermeto Honório Carneiro Leão e de Paulino José Soares de Souza, responsáveis pela mediação entre eles próprios e os escritores José Mármol e Domingos Faustino Sarmiento, assunto a ser retomado no fechamento deste artigo. 


\section{Joaquim Norberto e o enunciado comparativo do perspectivismo interamericanista}

A prática do enunciado comparativista norbertiano, apesar de sua emergência insular e individual no meio letrado brasileiro dos oitocentos, produziu bem mais que um trivial cotejo, vinculando-se ao grupo do Minerva Brasiliense, um dos principais veículos para o debate sobre a nacionalidade da literatura no Brasil. Em meio ao processo de recepção do texto norbertiano, quer dizer, quando deixava de ser uma dicção individual para vir a ser circunscrita em uma coletividade a render uma comunidade de leitores, uma coletividade notavelmente transnacional, sublinhe-se de passagem, tal enunciado irradiou mutuamente as literaturas argentina e brasileira por meio de um procedimento crítico e comparativo que nomeio perspectivismo interamericanista (Cf. DINIZ, 2017).

O registro fundacional norbertiano apareceu no texto "Indagações sobre a literatura argentina contemporânea”, publicado em 15/4/1844, no número dez do jornal Minerva Brasiliense. Ressoou entre os românticos argentinos exilados no Rio de Janeiro, antes mesmo alcançando outros compatriotas radicados em Montevideo. É o que logo veremos a propósito de Esteban Echeverría que, recebendo em Montevideo o artigo "Indagações...", estimularia Juan María Gutiérrez, na ocasião desterrado em Pelotas, a procurar Norberto no Rio de Janeiro. Seria assim promovida uma sociabilidade sem precedentes, a qual, dali por diante, ganharia entre nós proporções epistemológicas inadiáveis.

O enunciado comparativo referente ao que estamos aqui denominando perspectivismo interamericanista emergiu das "Indagações..." desviando com inediticidade a análise da relação determinista entre fonte (Europa, i.e., as literaturas da placenta colonial, Espanha e Portugal, assim como dos centros consignatários das literaturas periféricas, especialmente a Paris do séc. 19, farol dos romantismos argentino e brasileiro, mas também da Inglaterra e da Alemanha) e influência (Argentina, Brasil, enfim, as literaturas americanas como um todo ao longo da emancipação política do séc. 19).

Foi a partir do registro comparativo textual norbertiano que as ações do nosso binômio passariam a inscrever um ponto lateral na notação formal (cujo fundamento é a dialética hegeliana) $\mathrm{A}=\mathrm{A}$ porque $\mathrm{A} \neq \mathrm{B}$. Na léxis comparativa do perspectivismo 
interamericano, a ser detalhado a continuação, seria aberta uma via a encaminhar um modo enunciativo, entrecruzado, capaz de problematizar a base argumentativa da tradição comparativista europeia. Tal percurso forneceria sem precedentes substratos historiográficos e comparativos que, mais tarde, potencializariam o gradual questionamento da constituição pré-identitária dos comparatismos iniciados no séc. 19, característica de uma época em que a Linguística Comparada começava a se normatizar como uma disciplina moderna e cuja produção de saber/poder rapidamente passaria a chancelar o grau de historicidade das primeiras literaturas nacionais descentralizadas em relação ao eixo europeu, como corresponde ao caso brasileiro nos inícios dos oitocentos. É precisamente algo dessa ordem, ou seja, aquilo que se está chamando de enunciado comparativista do perspectivismo interamericano, o que se pode visualizar no corpo documental constituído pelas fontes primárias a serem interpeladas no correr deste texto. Veremos que as ações literárias bilaterais entrecruzadas a seguir estiveram ocupadas da suplantação de um regime de diferença abstrata, um regime indiferente às qualidades idiossincráticas apresentadas por A e B, visto que, na notação de linhagem hegeliana, $\mathrm{A}$ sempre precederá $\mathrm{B}$ para legitimar a equação $\mathrm{A}=\mathrm{A}$ porque $\mathrm{A} \neq \mathrm{B}$ (esquema que serviu de base analógico-analítica para todo comparatismo europeu dos oitocentos, tendo por epítome o conhecido conceito goethiano da Weltliteratur).

Sob tais termos é que se pode visualizar por detrás do procedimento das trocas literárias entre Argentina e Brasil emergentes do século 19 uma elisão da notação produtora de registros discursivos de formação que não poucas vezes obstruíram a assimilação da figuração social específica do objeto poético criado nos campos literários americanos, obstrução que se estenderia pelos mundos africanos e asiáticos até as reivindicações pós-coloniais que estouram na segunda metade do século 20.

Demarcada a definição conceitual com que de imediato queria iniciar, a ser mais à frente suplementada com tantos exemplos quantos se puder fabricar ao interpelarmos as fontes históricas, é importante notar que do enunciado comparativista norbertiano, assim como do perspectivismo interamericano produzido pela sua rentabilidade comparativa ressoante nos argentinos, decorreria uma deliberada aliança literária entre ambos os meios letrados. Mais notavelmente ainda: quanto às nossas duas literaturas, o processo das partilhas literárias interamericanas teria levado à invenção das possibilidades de saberes e poéticas que, em curso de autonomização pelo viés da americanização, passariam a coexistências específicas (homologias associativas 
transidentitárias) que não mais se deixariam determinar tão-somente pelas correspondências de relações genéricas (homologias de filiação pré-identitária).

Se o inusual procedimento comparativo interamericanista não chegou a tornar desnecessárias, abalou fortemente as exclusividades nominais do referente metropolitano ou do cânone europeu (cujo comparativismo encontrou-se determinado pela analogia da proporção), assim irradiando a institucionalização própria de nossas literaturas (cujo perspectivismo passou a ser regido pela proporcionalidade) em um campo interamericano simultaneamente a entrada no mercado mundial (europeu) das letras.

Voltando à quaestio das “Indagações...”, de Joaquim Norberto, sendo ela filha de seu próprio tempo, cabe dizer que registrou mais uma crítica impressionista (o floreio verbal típico daqueles tempos) do que uma crítica literária especializada (concebida por critérios estéticos teoricamente fundamentados). A nossos olhos anacrônicos tudo parece beirar ao juízo de valor, não poucas vezes pautado ou por um obsoleto critério de gosto ou por acusações embasadas em um nacionalismo ufanista ou em sua relação fisiológica com mecenato monárquico. Muito mais importante, contudo, é o seu gesto atemporal, contido em potência, por ser bem mais produtivo do que a solução que se apresentava em ato, isto é, importa não pelas sentenças críticas datadas, e sim pelo fabrico consciente do enunciado ao qual devemos a emergência de um comparatismo entrecruzado pela primeira vez interamericanista, disseminado nos meios argentino e brasileiro.

Publicada originalmente nas páginas do Minerva Brasiliense, as "Indagações..." pertencem a uma série de textos e excertos de palestras dedicados ao debate da nacionalidade da literatura que o jornal brasileiro vinha publicando desde o seu primeiro número. A tarefa das "Indagações..." assumia para si o trabalho de uma síntese, então inédita inclusive no meio argentino, enfocada na produção poética rio-platense a partir de uma abordagem que visava à poesia da geração da emancipação política e, ainda, se atentava para os primeiro ganhos estéticos devidos à Geração de 1837. Para o primeiro caso, foram consideradas as produções de poetas como Esteban de Luca, Vicente Lopez, Bartolomé Hidalgo e os irmãos Florencio Varela e Juan Cruz Varela. Tais produções foram consideradas por Norberto dignas de uma guinada na formação da literatura argentina. $\mathrm{O}$ escritor brasileiro viu nelas composições que teriam levado da emancipação política, isto é, da descoberta de tópos literário, à emancipação poética. As operações consolidadas pelas primeiras resoluções libertárias da matéria linguística na 
literatura argentina estariam, conforme a visão de Norberto, em Esteban Echeverría, autor cuja obra serviu de sinédoque à argumentação do texto referido.

Há em parte exemplos de um comparatismo improdutivo nas "Indagações...", quer dizer, de um comparatismo que mais não teria feito senão depreciar um dos objetos em foco pela superioridade de outro, revisitando a prática de um comparatismo colonialista. É o que se exemplifica no cotejo entre o poema "A la victoria de Chacabuco", de Esteban de Luca, e o poema "Transfigurações do Pão de Açúcar", de Alvarenga Peixoto, reiterando-se a mesma linha argumentativa quando, ato seguido, se atacaria a Juan Cruz Varela, autor de um poema que "insultava o fundador do quinto império" e cobria "com injúrias o nome dos brasileiros" (SOUSA SILVA, 1844: 300). Há em outra parte exemplos de comparatismo produtivo, quer dizer, interamericanista, quando se tomam os dois meios como produções de poéticas que, em proporcionalidade, poderiam se retroalimentar no processo de autonomização. É o que ocorreria ao se entrecruzar Florencio Varela e Antonio Pereira de Souza Caldas e, sobretudo, Echeverría e Gonçalves de Magalhães. Em qualquer caso, o enunciado norbertiano dinamizou uma mutualidade de repertórios nacionais americanos e europeus, quer argentino (uma lista homogeneizadora que, enfocando o tema patriótico para além dos casos já citados, acolhe, em âmbito lírico, as poesias de Juan Ramón Rojas, Juan Crisóstomo Lafinur, Cayetano Rodríguez e de Manuel José de Lavardén, e, em âmbito ensaístico, os começos da historiografia nacional argentina, a cargo de Gregorio Funes e do napolitano Pedro de Ángelis), quer brasileiro (listando, para além de Gonçalves de Magalhães, Caldas, Alvarenga Peixoto, o nome de Gregório de Matos, bem como "o futuro destino da pátria dos Rabelos, Negreiros, Camarões, Henrique Dias, Benevides, Albuquerques, Coelhos e tantos outros e outros”), quer lateralmente francês (com deliberada simpatia pelos papas do romantismo gálico, Victor Jugo e Lamartine, intercalados, com notável antipatia prescrita pelo escritor brasileiro, com o intelectualismo liberal de Voltaire e Condorcet).

Tudo isso implicou, conforme já chamava a atenção Félix Weinberg (1961: 3536), que o enunciado comparativista das "Indagações..." viesse a constituir paralelos interamericanos inteiramente originais. Daí uma sorte de procedimento que, em nosso entendimento, procuraria refundar um centro literário em função da margem americana - e não o contrário, declinando da praxe do comparatismo oitocentista.

De um modo geral, podemos entender o plano de composição das "Indagações..." da seguinte maneira: a primeira prateleira de poetas argentinos, já 
listada acima, estaria simplesmente ocupada em cantar os feitos patrióticos, tentativa de imortalizar os atos emancipatórios, enfim, uma libertação de poética temática, mas não em espessura gramatical ainda; a segunda prateleira, ou melhor, a obra-sinédoque que operou uma inflexão de ordem linguística, estaria na produção de Esteban Echeverría. Ou ainda como aparece no próprio texto, irrigado por conjunções e paralelismos que deixam nítida a necessidade de uma autogênese interamericana:

Em geral, a linguagem e o estilo destes poetas [De Luca, Hidalgo, os Varela, etc.] é sempre a mesma; toda a poesia resume-se em uma eloquência declamatória e toda vã, em versos sesquipedais e em grandes palavreados floridos contra os tiranos da América, sem beleza alguma notável, muito mais eficaz para incitar os ânimos do que para recriá-los; [...].

[...]

[...] Mas os tempos passaram, e os cantos do vate da irreligiosidade levaram por selo a excreção e o esquecimento; e as Harmonias dos Dellamartines, e os Suspiros dos Magalhães ecoaram nessas margens majestosas onde essa voz outrora tão potente trovejara, e os povos escutaram essas harmonias, e escutaram esses suspiros, e Esteban Echeverría aparece como o crepúsculo de um belo dia, tímido ao princípio antes às trevas de uma longa noite, e pouco e pouco se reanimando com a luz que ela reflete, e eis por fim o dia que dissipa as sombras, e nova época desponta na literatura argentina, que toma uma fisionomia mais Americana, com menos visos de espanhola, e mais interessante, por isso mesmo que se tornar original.

É Esteban Echeverría o Magalhães argentino; e uma análise de suas obras, que publicaremos a bom tempo, fará compreender as felizes reformas que ele vem de executar na literatura de sua pátria; mostraremos então que novos satélites da moderna escola começam de aparecer... [...]. (SOUSA SILVA, 1844: 298-301).

Norberto não chegou a escrever o estudo prometido ao final das "Indagações...". Ausência que, contudo, não impediu o propósito do texto. O artigo encontraria no desterro montevideano o mentor do romantismo argentino, Esteban Echeverría, escritor cujas proposições se destacaram no Salão Literário organizado em Buenos Aires, em 1837, pelo livreiro Marcus Sastre, célebre encontro que marcou o espaço de sociação da geração responsável pela emancipação da língua literária do país. 
A primeira recepção do texto norbertiano por parte do meio letrado argentino está registrada no epistolário de Echeverría com Juan María Gutiérrez. São eloquentes os detalhes que o entrecruzamento desses documentos e outros mais que aparecem gradualmente nas sessões seguintes, conforme passamos a ver aqui.

\section{Echeverría e Gutiérrez, receptores do enunciado norbertiano}

Em uma carta trocada entre Echeverría e Gutiérrez, com data em 24/12/1844, enviada de Montevidéu ao Rio Grande do Sul, cidades em que ambos argentinos se encontravam desterrados, o primeiro comentava a leitura que havia feito das "Indagações ...":

En el número 10 de la Minerva Brasilense hay un artículo sobre la literatura argentina que debe llevar a Chile y publicarlo. Hay muchos aquí que desearían ver la continuación prometida. Procure relacionarse con el autor de ese artículo y estimularle a continuar sus indagaçoes [sic]. Nos conviene mucho el juicio (que no puede ser sino imparcial) de los extranjeros. Es el modo de confundir a los envidiosos y a los pandilleros.

El autor de ese artículo manifiesta buen criterio literario y un conocimiento poco común, aun entre nosotros, de la literatura argentina. [...]. Contiene además verdades que ninguno de nosotros se ha atrevido a proclamar por no herir a los que no han perdonado medios para desconceptuarnos; y entretanto si no se dice la verdad, la literatura no puede adelantar porque el pueblo no tiene criterio propio, y ni las obras ni los talentos jamás serán apreciados debidamente. $[\ldots]$

Voy a ocuparme pronto de una Mirada retrospectiva sobre el movimiento intelectual en el Plata desde el año 30 en adelante. Precisamos inventariar lo hecho para saber dónde estamos y quiénes han sido los operários (Montevideo, 24/12/1844).

Por meio do imperativo do verbo "dever", Echeverría estimulava Gutiérrez a levar consigo o artigo de Norberto ao Chile, para por lá tentar publicá-lo. Estava por trás disso a tentativa de combater, mediante intervenções interamericanas dos conterrâneos expatriados, o autoritarismo político e editorial de Rosas, governante que havia fechado para a cena política argentina unitarista o espaço democrático, assim interditando a 
esfera pública em emergência no país. Ainda, incitava Gutiérrez à sociação com Norberto e com o círculo letrado fluminense. Para Echeverría, a opinião do crítico brasileiro, ainda que vinculada à monarquia imperial, era, de modo geral, elogiosa e simpática à causa dos unitários e dos escritores da Geração de 1837, exilados em pelo menos quatro áreas sul-americanas: Bolívia, Brasil, Chile e Uruguai. Emergia do enunciado perspectivista norbertiano algo novo, para o qual Echeverría passaria a militar ainda que sem atinar completamente.

Que um crítico não argentino, vinculado ao regime monarquista do Brasil Império, falasse então positivamente da literatura argentina, endossando a sua nacionalidade e, parcialmente, invocando as suas últimas inovações estéticas, portanto, era algo que viria a contribuir para a interamericanização da causa unitarista, a restituição do republicanismo platino em plano político e, em plano estético, a legitimação da poética de uma literatura que apenas começava a esculpir a sua língua literária. Desse modo, as "Indagações..." davam conta de um panorama historiográfico inédito acerca da poesia patriótica de formação nacional e do início do romantismo argentino. Echeverría percebeu toda a potência do ato enunciativo veiculado pelo entrecruzado comparatismo norbertiano, a ponto de confessar a seu correspondente, Gutiérrez, que se ocuparia ele próprio de uma historicização destinada à recente produção literária argentina, revelando inclusive o nome pretendido para o trabalho que nomearia "Mirada retrospectiva". Tudo indica que Echeverría havia vislumbrado tal tarefa mediante a leitura do escritor brasileiro, assim comprometendo-se a fazer um balanço da produção da década de 1830 em diante, período a que se destinaria o estudo também prometido por Norberto ao fim das "Indagações...".

Gutiérrez foi inicialmente parcimonioso frente ao juízo positivador de Echeverría. Desde 21/3/1841, conforme carta enviada ainda quando estava em Montevidéu, trataria de deixar Echeverría avisado sobre os planos de ir ao Rio de Janeiro, com a intenção de tomar um navio que cruzasse o Cabo de Hornos em direção à costa chilena. Uma série de contratempos impediria Gutiérrez de concretizar em curto tempo o traslado, o qual, desde o aviso em 1841, só viria a se concretizar entre dezembro de 1844 e janeiro de 1845. Em 1/2/1844 escreveria comunicando estar em Pelotas. Considerava trabalhar como agrimensor na cidade sulina. A atividade intelectual era escassa naquelas latitudes. Gutiérrez lamentava a existência de apenas um único jornal em Pelotas, O Commercio. Isso o desaminava enormemente, ameaçando com “uma vida vegetativa e de puro desterro". Não pararia de comunicar o 
quadro desanimador ao amigo por meio de várias cartas, aconselhando enfaticamente que jamais viesse ao Rio Grande do Sul, caso se tornasse necessário para Echeverría deixar Montevidéu e exilar-se em outra latitude. Mesmo em Porto Alegre, cidade mais desenvolvida do que Pelotas, Gutiérrez não se reconheceria animado com as oportunidades de exercer atividade letrada. A falta de oportunidades de trabalho na imprensa sul-rio-grandense seria assim um obstáculo para os seus planos. Por isso, considerava mais produtivo o exílio no Chile, país com uma imprensa, segundo escreveu a Echeverría em uma carta de 7/8/1844, "muito adiantada e decente", e, além do mais, onde já se encontravam Juan Bautista Alberdi e Sarmiento, ambos dispondo de visibilidade nos meios chilenos.

Em resposta ao apelo de Echeverría, em carta datada a 30/1/1845, enviada já a partir do Rio de Janeiro, informava que, apesar de ainda não ter conseguido o número do Minerva Brasiliense em que pudesse ler as "Indagações...", manteria o pé atrás com relação à opinião de Norberto, autor que, apesar de considerar parcialmente os elogios de Echeverría, parecia digno de crítica por ter atacado ferinamente a outros poetas patrióticos pelos quais Gutiérrez tinha manifesto apreço:

No he podido obtener todavía la Revista o Minerva Brasilera [sic] que se ocupa de nuestra literatura; pero no puedo persuadirme que sea exacto, aunque se haga justicia a algunos de nuestros escritores. Yo me propongo publicar donde pueda mis estudios continuos sobre nuestra literatura; los poetas de mi patria, así como los guerreros de la Independencia, son mis héroes, mis amores, mis lares, y he de hacer cuanto pueda por su gloria. Mi crítica no es la de usted; yo no pongo de vulto sino lo bueno; así estoy sentido con usted para el palo que le ha dado a mi viejo López al juzgar su Himno que como la Marsellaise francesa tiene de todos el respeto de un estandarte agujereado por los enemigos, pero salvado por la victoria. (Rio de Janeiro, 30/1/1845).

A reserva de Gutiérrez, além de se formular pelo desgosto de encontrar Vicente López e demais poetas patrióticos depreciados por Norberto, mediante critério tão infundado quanto aquele que viria a sustentar o contragolpe pretendido pelo argentino, parece ter querido se justificar também pelas pretensões que ele mesmo estimulava em si quanto a escrever, a exemplo de Echeverría, a súmula historiográfica da recente produção 
literária argentina em formação; tarefa em que Norberto, um brasileiro supostamente monarquista, se adiantara aos argentinos republicanos.

Quiçá por isso as ressalvas prévias quanto às “Indagações...". Mas tal opinião e outras mais (a concepção de um Brasil como país de vida intelectual raquítica é um bom exemplo) logo começariam a ser alteradas quando o polígrafo argentino finalmente viesse a se encontrar na capital imperial. A visão que Gutiérrez passaria a ter já no Rio de Janeiro não seria mais o areal desértico que noticiara a Echeverría nas cartas enviadas a partir de Pelotas. Iniciaria a falar das riquezas materiais, assim como das atividades culturais presenciadas por ele na corte fluminense, a ponto de escrever em 30/1/1845 (data da primeira carta enviada a Echeverría a partir do Rio de Janeiro) que havia encontrado uma cidade "verdadeiramente europeia".

Ainda mais significativo seria o que Gutiérrez passaria a opinar sobre o meio letrado brasileiro. Se antes, enquanto se deslocava entre Montevidéu, Pelotas e Porto Alegre, denegara a cena letrada brasileira e, sobretudo, a perspectiva comparativista das "Indagações...", sem sequer tê-la lido até aquela ocasião, no Rio de Janeiro, em contrapartida, quando se encontrava à espera de navio que o levaria ao Chile, estreitaria relações com Norberto e, por consequência, com o importante grupo do Minerva Brasiliense. Daí por diante se disporia a suplementar ou a reparar mediante publicação própria o que considerou equivocado ou ausente na perspectiva das "Indagações...", bem como a suprir com material bibliográfico a produção crítica que o brasileiro prometera continuar publicando acerca da literatura argentina contemporânea. É o que se pode ler numa carta de 25/2/1845:

A pesar de lo que dije a usted en mi anterior traté de ponerme en relación con el autor de las Indagaciones sobre la literatura argentina. Me pareció que el mejor medio era escribir unos apuntes sobre el mismo asunto para llenar vacíos y rectificar juicios equivocados de que abundaba la Minerva, dedicándolos al autor del artículo. En consecuencia, ayer recibí la visita del señor Joaquín Norberto de Souza Silva, el cual es un joven modesto entregado de buena fe y con buenos antecedentes a la cultura de las letras; [....]. Es autor de varias otras obras. Hablamos de usted y me dijo que iba a escribirle; pero me parece que debe usted hacerlo antes mandándole sus obras que él tiene muchos deseos de leer. Vive en Nycteroy [sic], Rua d'el Rei N. ${ }^{\circ}$ 55. También puede mandar su carta y libros a la Rua do Ouvidor, Albino y Jordan, divisa del libro azul, donde va frecuentemente Souza Silva. 
Está traduciendo mis apuntes para la Minerva; es preciso que usted no descuide esta relación porque puede ser importante para en adelante. Yo trato de acopiar cuantos materiales puedo para conocer la literatura de este país que algunos niegan, pero sin razón; hay hombres de capacidad y sobre todo de imaginación. Por otra parte, cuanto se dijese sobre este asunto sería completamente nuevo en nuestras Repúblicas.

Aún no tengo esperanza de salir de aquí, esto me aflige, aunque me gusta mucho Río Janeiro.

Até o presente momento não se conhece a existência de correspondência epistolar entre Echeverría e Norberto, nem tampouco entre o brasileiro e Gutiérrez, apesar de os dois últimos terem se frequentado no Rio de Janeiro do século 19. As três ações se enredaram em registro epistolar apenas no que intercambiam os dois argentinos. Tampouco se publicou em algum número do Minerva Brasiliense os "Apuntes" de Gutiérrez em que supostamente trabalhava Norberto segundo a correspondência. A verdade é que anteriormente às trocas interpessoais de Gutiérrez e Norberto, bem como anteriormente à leitura de "Indagações...", ambos estavam a meio passo de um campo mórfico das afinidades críticas eletivas que se conformariam apenas na sequência dos anos imediatos.

Gutiérrez registraria em uma carta em 7/8/1844, endereçada a Echeverría ainda a partir de Porto Alegre, aquilo que pouco antes, em 15/3/1844, comparecera no enunciado comparativo norbertiano, quando as "Indagações...” saíram do prelo:

Aquí está en clase de secretario de Gobierno el Director Magallanes [sic], a quien se le reputa primer poeta brasileiro [sic]; le trato con frecuencia. La carrera de este joven tiene algo de parecida con la de usted. Estudió en Europa; a su regreso dio a conocer, bajo el título de Suspiros poéticos, un libro de poesías bajo la inspiración moderna, muy lleno de recuerdos de la patria, de mucho amor a la libertad y de pensamiento en Dios. [...] La juventud brasileira $[\mathrm{sic}]$ hace fuerzas por la independencia de la literatura, pero tienen algo de flojo los ensayos. Redactan la Minerva Brasílica [sic] con este objeto. [...]. El vizconde de S. Leopoldo, autor dos Anaes da Provincia de Río Grande, también está aquí y le trato. 
Como quem fizesse uma análise das condições sociais e históricas que permitiram a aclimatação do romantismo na Argentina e no Brasil, Gutiérrez espelhava Echeverría e Gonçalves de Magalhães, contrabandistas mentais da tendência europeia para as Américas após a temporada disfrutada por ambos em Paris. É justamente o ponto comparativo acionado meses antes por Norberto, ponto sobre o qual, pelo que consta, o brasileiro não voltaria a escrever aproximando tão enfaticamente o par literário transnacional Argentina e Brasil. Ao contrário da aparente procrastinação de Norberto e de Echeverría, Gutiérrez, sim, voltaria a explorar o perspectivismo interamericanista articulando Echeverría e Gonçalves de Magalhães. Isso ocorreu no estudo que se chamou "A Confederação dos Tamoyos, poema por Domingo Gonçalves de Magalhães".

O trabalho que o polígrafo argentino dedicou ao poema A confederação dos Tamoios (1857) partia do argumento comum à geração da emancipação republicana: a revisão/denegação nacionalista da produção literária relativa ao período colonial em função de se considerar a poética prévia às independências republicanas uma produção toda ela desprovida de consciência política americana. Analisando as inflexões estéticas de A confederação dos Tamoios, Gutiérrez informava que o poema de Gonçalves de Magalhães teria levado à emancipação linguística e ao ganho de consciência nacional, razão pela qual a poesia brasileira seria por ele situada em posição superior no rol da poesia indigenista americana, cujos exemplos são La araucana (1569), de Ercilla y Zuñiga, Lima fundada (1732), de Pedro Peralta, e El peregrino indiano (1605), de Saavedra Guzmãn.

Gutiérrez assim começava a operar por meio da lógica do perspectivismo interamericanista - denominado por ele "sincronismo histórico" -, cotejando a obra de Echeverría com a de Magalhães:

[...] el sincronismo histórico entre una y otra literatura viene a ponerse de bulto, es cuando se personifican en D. Esteban Echeverría, y en el Sr. Magalhães, autor del poema cuyo título encabeza este escrito.

[...]

El Sr. Magalhães apareció como Echeverría cuando menos se le esperaba, trayendo como este el sentimento, el colorido, la melancolia y el perfume religioso que transpiran en las composiciones de Chateaubriand y de Lamartine. 
$[\ldots]$

"Quien presume conocer bastante (observa el poeta [Gonçalves de Magalhães]) los instintos de semejantes seres y los mistérios íntimos de la vida, para afirmar o negar estas aparencias"?

Parece que en este rasgo tradujese el Sr. Magalhães aquellos conocidos versos del epílogo de la Cautiva:

"Quizá los sueños brillantes/ De la inquieta fantasia,/ Forman coro em la armonía/ De la invisible creación”. (GUTIÉRREZ, 1860: 235-236-247).

O "sincronismo histórico" da crítica de Gutiérrez apareceu empenhado em projetar entre um campo literário e outro os ganhos linguísticos do romantismo americano. Pretendia comunicar um plano de composição que já teria levado à emancipação poética intra/supranacional, com isso afirmando a constituição de uma linguagem literária e uma literatura nacional tanto na Argentina quanto no Brasil, validando reciprocamente ambos os lados por meio do palimpsesto que se revelava ao sobrepor os dois poemas.

O indigeníssimo classicista de Magalhães entra daí por diante em ressonância estética com as artificialidades linguísticas presente em La cautiva (1837), poema precursor do romantismo argentino mediante o qual Echeverría (2013: 49-50) veio a dotar a paisagem nacional de traços psicológicos característicos à ideologia unitarista, falando, como se lê nas estrofes iniciais, de um “deserto incomensurável”, dotado de um "triste semblante, solitário e taciturno", assim expondo, conforme as estrofes de entrada, a questão romântica por excelência: “¿Qué lengua humana alabarlas?”. Ou seja, uma língua humana, uma língua artificial, literária, deveria ser composta para então se edificar a paisagem verbal da poesia nacional.

É interessante notar que em Gutiérrez o desterro, o deslocamento do exílio e a sociabilidade na capital imperial aqueceriam - além de uma reconfiguração da imagemBrasil, algo que na sua correspondência com Echeverría oscilara entre o areal desértico e bárbaro (Pelotas e Porto Alegre) e a capital cosmopolita e civilizada (Rio) - uma guinada na definição de literatura americana característica à sua obra de historiografia literária. As razões quanto ao primeiro rechaço à produção brasileira já se expuseram acima: os vínculos monárquicos do autor de "Indagações..." e a crítica do mesmo aos poetas patrióticos da Argentina, os mais caros e inspiradores da Geração de 1837. Tal prática começaria a ser alterada quando Gutiérrez passasse ao Rio de Janeiro. Mas é algo intermitente. Pareceu ter retornado (ou talvez não de todo eliminado) quando 
Gutiérrez viesse a se encontrar em Valparaíso, cidade chilena em que publicaria América poética. Primeiramente, a antologia começou a ser publicada sob a forma de fascículos de até 48 páginas, os quais eram enviados aos assinantes à medida que iam sendo publicados. Resultou daí um volume final, publicado em 1846 na cidade de Valparaíso, com mais de 800 páginas, abrangendo 455 poemas de 53 autores de distintos países americanos. Todos os poetas publicados em América poética eram exclusivamente extraídos do raio linguístico hispano-americano.

Cabe dizer então que, em um primeiro momento, Gutiérrez excluiu - ou pelo menos adiou - o Brasil de sua América poética (1846), e, em um segundo momento, incorporou a literatura brasileira em sua categorização tardia (e mais conceitual) da literatura americana, conforme víamos no estudo crítico dedicado ao poema $\mathrm{A}$ confederação dos Tamoios, texto que, emparelhado com o poema La cautiva, permitiulhe tramar, como antes fizera Norberto, algumas reverberações bilaterais entre as produções literárias do meio argentino (e outras áreas americanas) e o meio brasileiro.

Essa guinada - a partir da qual Gutiérrez se encontraria definitivamente com o enunciado norbertiano - implicou algo relevante no que toca ao ajuste epistemológico do perspectivismo interamericanista: a saída de uma categorização crítica e historiográfica determinada pela noção de um intercontinentalismo poético pautado apenas pela ideia de nação e literaturas nacionais (hispano-americanas) e a entrada em uma conceitualidade crítica e historiográfica intensificada pela concepção mais porosa de literaturas e áreas culturais afins (inicialmente, as intensidades chilenas, peruanas e rio-platenses sincronizadas nas paisagens verbais dos poemas indigenistas La araucana, Lima fundada e El peregrino indiano; enfocadamente, as reformulações interculturais das sincronicidades verbais visualizadas na sobreposição dos planos de composição de A confederação dos Tamoios e de La cautiva). Assim o posicionamento inicial de Gutiérrez, conforme líamos nas cartas enviadas a Echeverría antes de se encontrar no Rio, resultaria alterado, abrindo-se verdadeiramente para aquela sentença que o autor de La cautiva lhe gritara mediante uma carta que viria a alcançá-lo já na capital imperial: "Mi obra", escreveu Echeverría, "no es local sino americana, porque es uno el espíritu y la tendencia de la revolución de los pueblos sudamericanos”. Em suma: a conceituação de literatura americana, em Gutiérrez, deixaria de ser apenas um sentimento de pertencimento ontologizado, um estar na América, para redimensionar-se com a busca de uma unidade cultural interamericana, para além da restrição hispânica. 
Gutiérrez veio a acolher o Brasil em sua reformulação conceitual da literatura americana somente a partir do momento em que Rosas já se encontrava deposto pela ofensiva comandada por Justo José de Urquiza. O governo imperial do Brasil teve interesse declarado e participação direta no evento. A partir de 1851, por meio das ações diplomáticas de Carneiro Leão (Visconde do Paraná) e Soares de Souza (Visconde do Uruguai) em Montevidéu, foram confirmadas as alianças entre o Império do Brasil, a República Oriental do Uruguai e as frentes rebeladas das províncias de Corrientes e Entre Ríos, as quais se encontravam reunidos sob a ofensiva antirrosista do general Urquiza contra o mandatário da Confederação Argentina.

Tais alianças políticas estão completamente associadas às definições da autonomização do campo letrado interamericano ao longo do século 19. São elas que fizeram com que os escritores republicanos, argentinos, deixassem de condenar os escritores brasileiros, vinculados à monarquia, para assim desenharem uma linhagem de vínculos interamericanistas. Nesse sentido, dois outros episódios, relativos à sociação de Sarmiento e Mármol e os dois membros do quadro diplomático do Brasil Império (os viscondes do Paraná e Uruguai já nomeados) são eloquentes quanto à ressignificação do exílio e a produção de ações de transnacionalidade que teriam levado à formação discursiva da prática do perspectivismo interamericanista . Vejamos por fim este quadro documental a sustentar a teorização conceitual aqui vislumbrada.

\section{Sarmiento, Mármol e as negociações bilaterais com a diplomacia imperial}

Assim como havia ocorrido a Echeverría e Gutiérrez, Domingo F. Sarmiento e José Mármol, vinculados direta ou indiretamente à Geração de 1837, foram levados ao exílio durante o período rosista de fechamento democrático na Argentina. Ambos pretenderam incialmente o Chile como destino. Porém Mármol (diferentemente de Sarmiento) nunca chegaria a Santiago, embora a partir do Rio de Janeiro haja tentado zarpar em direção ao destino santiaguenho nunca alcançado em razão de um iminente naufrágio no Cabo de Hornos, assim tendo de regressar ao Rio e ali permanecer até 1951, quando finalmente passou a Montevideo ano antes de ser concluído o seu exílio e encontrar lugar na Argentina a partir de 1952. 
Vindo do Chile, Sarmiento fez uma primeira visita ao Rio em 1846. Durante o momento de contato inicial - conforme carta escrita a Miguel Piñero e reunida no livro Viajes (SARMIENTO, 1997: 56-74) - todos os seus juízos são depreciativos. O monarca brasileiro é descrito como um idiota, fazendo repetir a caricatura que ouvira de Pedro II, bem como o sol tropical é descrito como ameaças tirânicas, concedendo apenas admiração à visão sublime do Pão de Açúcar a partir da praia de Botafogo. Resumidamente: ainda em 1946, Sarmiento participa e compõe o juízo republicano dos argentinos antimonarquistas exilados no Brasil. A desconfiança veio a ser diluída apenas em 1952, quando a politica externa brasileira estaria declaradamente alinhada com os propósitos da remoção do governo rosista e Sarmiento finalmente se encontra com Pedro II.

Sarmiento retornaria ao Rio em 1952 com intenção de logo mais entrar na Argentina após a temporada de exílio no Chile, hospedando-se em Botafogo na casa do uruguaio Andrés Lamas. Referente a esse episódio, encontramos no Setor de Manuscrito da Fundação Biblioteca Nacional uma carta enviada a Paulino José Soares, nomeado visconde do Uruguai e responsável pela ação diplomática na região rioplatense durante o combate a Rosas. $\mathrm{O}$ assunto do documento em questão é riquíssimo e pede ser transcrito em extensão:

Rio de Janeiro Abril 14 de 1852

Mi distinguido y amable amigo:

(A Paulino-Uruguai)

Le escribo a V. con los recuerdos frescos aun de las agradables conferencias que he tenido con S. M. el Emperador en su residencia de Petrópolis, repetidas, solicitadas algunas, y todas francas, llenas de indulgencia, y con un abandono de parte de S.M. que más honor hacian a la elevación de su caracter, que el que a mi me dispensaba, que era inmenso.

Recordará V. que venia exasperado con los tratamentos descorteses de [ilegível], a quienes en condiciones iguales no tomaríamos para que nos limpien las botas, porque ni eso saben, y [ilegível] V. imaginas el efecto balsámico que ha debido producirme este episodio de mi vida y que se coloca entre los más gratos recuerdos.

Deciame el señor Carneiro, que era reservado por caracter y que lo estimulase a abrirse conmigo. No se lo que ha sucedido, pero me acordaba de una frase de V. hablabamos ambos horas enteras, disputadonos la palabra, 
salira la multitud de cuestiones interessantes, [ilegível], inmigraciones, poesía, caracteres nacionales [abreviatura].

Conoce todos mis escritos y me ha hablado de cuanto detalle de personas e incidentes se encuentran en ellos. Gustaba mucho de los caracteres que he trazado aqui y allí en mi biografia, y me indicaba que los reuniese en uno solo libro. Indiquele algunos que no conocía, pidiomelos; pero se desconcestó un poco cuando le dije: estan en un libro que no deseo que lea S. M. Entonces me dijo pongame señales de lo que quiere que no lea y cuente V. que no lo leré! Imaginase V. amigo cuanto hay de sencillamente noble en este abandono. Mandole el libro, sin indicarle nada para que lo leyese todo, pues me [ilegível] después de los incidentes, mismo que por su frivolidad hubiera querido ocultar a sus miradas. Eran Recuerdos de Provincia.

$[\ldots]$

He sido condecorado con la condecoración de oficial de la Orden de la Rosa y a indicación mia los Coroneles Mitre y Paunero por habernos hallado en ella combate Naval del Tonelero. Juzgue V. por cuanto no hago más que indicarle, cual debe ser mi afección profunda y mi respeto por hombre tan altamente colocado, y tan noblemete enriquecido de las prendas que adorna en el caracter y el espiritu. Tendré un día ocasion de manifestarlo así en mis ulteriores trabajos.

He podido inferir por el examen a vuelo de pájaro que hago de la escena política que presenta el Río de la Plata que en buen y en mal las máscaras caen, y cada uno se presenta en su verdadero punto de vista. El edifício de la fusión, fundado sobre arena, se desmorona, y el arbol de sus frutas naturales. [...]. Lo de Buenos Aires es curioso, la prensa, la administración, las proclamas, los nombramientos, aquel hacer y deshacer, que muestran en el que dirije los manejos la petulancia de un niño, la incosistencia del barro, y la falta de ideas, de juicio, de tino. El resultado final es que retracta cuanto hace o dice, que y lo han aprendido a manejar. Tengo esperanzas de que estamos salvados, y que nada, nada se ha perdido.

Yo pernanezco aqui, hasta que las cosas de Montevideo estallen, y aquella ventolina se disipe. Estoy pues a sus ordenes.

Mando pues un folleto ad memorandum en que principio el fuego. Es solo para preparar el terreno, y sondearlo. Como conozco ya a mi adversario, estoy seguro de que mirará y tratará de evitar que le ponga la proa como a Rosas. Cuenten conmigo en todo lo que seja hostil al espiritu que domina la 
política general, y contraria nuestras afeccciones y simpatias havia V. y el Brasil.

$[\ldots]$.

D. F. Sarmiento

Achando-se então na possibilidade de ser acolhido no seio da política imperial de Pedro II e das relações exteriores conduzidas pelo visconde do Uruguai, Sarmiento revisa a tese da dialética entre a civilização (republicanismo cosmopolita) e barbárie (caudilhismo antirrepublicano) ao encontrar no Brasil imperial (após a derrubada de Rosas por Urquiza) algum gesto de adesão à causa unitarista, republicana. Sarmiento reconsidera, portanto, a opinião geral antes tecida sobre regência monárquica de Pedro II que, conforme a carta de 1846, equivaleria à pré-modernidade do regimento político caudilhista e antirrepublicano de Rosas. Sarmiento começa a rasurar a fronteira nacional em busca de uma unidade americana, perspectiva que permitiria a Geração de 1837 regressar à Argentina após o fim do regime rosista, logrando, além do mais, a primeira edição e publicação de seu livro Campaña en el Ejercito Grande Aliado de Sud America (1852) no Rio de Janeiro pela Imprensa Const. De J. Villeneuve.

Antes, em 1843, Mármol chegara ao Rio de Janeiro e ali permaneceria (a tentativa náufraga de ir ao Chile é de 1846) na capital do Império brasileiro até 1851, quando avançaria para Montevidéu. Entre as suas participações mais marcantes na vida literária e intelectual brasileira está o artigo "Juventude progressista do Rio de Janeiro", publicado em 1846 na revista Ostensor Brasileiro. Para Mármol, a literatura nacional não existia no Brasil Império, pois o país não havia "entrado na revolução americana". Daí o texto de Mármol ser concluído com uma efusiva convocatória à juventude carioca, tencionando fazê-la tomar para si a causa americana, isto é, endossar o republicanismo que se encontrava sob ameaça na Argentina.

Descontando as sentenças panfletárias de Mármol, algo de sua análise convém bastante para entendermos um ponto tocante à constituição da autonomia do campo literário e, especialmente, o procedimento das trocas bilaterais que se ensaiavam a meio caminho entre o século 19 e o 20. A sua crítica à imprensa brasileira da época imperial destinava-se à ausência de um assunto homogêneo na imprensa carioca. O poeta argentino exilado no Brasil, ao tramar para a causa americana, pressentia um ponto crucial para o procedimento constituinte da autonomia no campo literário: a separação das esferas do poder/saber da época, acrescida da profissionalização da figura do 
escritor. Mármol percebia que a depuração dos quadros - embora estreitamente comprometidos no seu século - tornava-se uma determinante para a especialização e, consequentemente, para a autonomização do campo intelectual então inexistente para ele em função do mecenato monárquico:

\begin{abstract}
Passemos ao periódico literário. Este escrito, que é em ponto menor que o folheto, se alimenta de duas fontes: da produção original e da crítica. Faltando a produção, falta a crítica em literatura; porém existe outro quadro imenso, outro livro, onde cada página, cada linha é um alvo de crítica para o periódico. Este livro é a sociedade com suas preocupações, suas tendências, seus hábitos e seus costumes. Tudo isto é uma propriedade do crítico, porém que só o periódico pode conter, porque todo o povo o lê e compreende; no entanto que levada ao livro, a crítica vem a ser uma dissertação pesada e ineficaz. (MÁRMOL, 2010: 425).
\end{abstract}

$\mathrm{Na}$ ausência de um mercado editorial viabilizador de um projeto de unificação letrada do espaço da nação emergente, a imprensa, para Mármol, deveria então cumprir a função de pôr em rotação e legitimar os signos republicanos. De modo que da presença de uma imprensa acrítica, tendendo menos à especialização que aos generalismos dos esboços impressionistas, como ele via a produção carioca à época, marcada pela publicação de miscelâneas, resultaria a ausência de conteúdos verdadeiramente nacionais, elementos capazes de promover uma emancipação do campo intelectual mediante um assunto que permitisse dinamizar a sociedade e a opinião pública. Era essa a debilidade que privara a juventude carioca de produzir, sob o olhar de Mármol, um movimento revolucionário e irruptivo tanto em âmbito político quanto literário.

Convém mencionar agora a existência de outro documento arquivado na FBN, diretamente relacionados às relações de Mármol e a sociedade brasileira, bem como a recepção de sua obra em nosso campo letrado. Transcrevo alguns trechos do documento:

\author{
/Confidencial/ \\ Ilmo. e [abreviatura ilegível] \\ 6 de jan de 1851 \\ 1852
}


Remeti pelo Paranaense [sublinhado] sete exemplares do número da Semana onde é habitualmente defendida a intervenção do Brasil nas questões do Prata. Como Va. Reconheceu convenientemente, pretendo retribuir ao autor, que promete continuar no mesmo empenho. Por uma pessoa da intensidade desse moço, e que me merece confiança, procurei saber qual o meio mais próprio de recompensá-lo por esses serviços: declarou ele que, posto [sic] precise muito de dinheiro, não o receberia pelos escritos com que nos tem obsequiado. Segundo essa pessoa, Mármol aceitará algum mimo de valor, e estimaria que prestássemos algum auxílio ao seu periódico.

Tenciono presenteá-lo com um relógio e [ilegível] no valor de 400 a 500, 000 de nossa moeda e tomar sete assinaturas da Semana, uma para o I. M. o Imperador e as outras V. Exa. E os seus colegas. E prestar-lhe-ei mais algum auxílio, se ele continuar a escrever a nosso favor.

Prometeu-me que nos próximos número da Semana responderá ao que Rosas fez publicar no seu Agente Comercial do Prata contra os tratados que acabamos de celebrar com este Estado; desmascarando as intrigas do ditador, mostrando a futilidade da acusação de monopólio comercial que segundo aquela folha temos em vista, e quanto aos limites com este Estado, sustentando que a Confederação nada tem que ver nesses ajustes, sobre que indiretamente se pronunciará a favor.

Os artigos do Agente Comercial del Plata pertencem, segundo presume Mármol, à pessoa de Guido. Se, como já ouvi a alguém, Mármol é filho de Guido, não admirará que ele tenha feito algum estudo do estilo desse escritor.

$[\ldots]$

Tenho a honra de ser

De VEa.

[assinatura]

Honório Hermeto Carneiro Leão

Montevideo, 6 de janeiro de 1851

1852

Acrescento ainda à transcrição do documento supracitado algo retido do rascunho à lápis encontrado junto à documentação acima citada para logo avançar na interpelação desta fonte: 
Acabo de fazer a Mármol o favor de aceitar 75 exemplares de suas Harmonías e 75 da Amalia para mandar vender no Rio de Janeiro, adiantando-lhe já o preço que são 300 patacões. Remeterei a V. Ex. pelo Paquete do Sul esses exemplares, e pedirei o pagamento do meu adiantamento. Mármol vai para Buenos Aires escrever um jornal, e pareceme bom conservar as boas relações em que estamos. Quando fui daqui para Buenos Aires dei passagem no Paraense a Alsina, atual ministro em Buenos Aires e a Diogenes, e mais cerca de 30 argentinos emigrados. [...] Dou ao Dr. Sarmiento uma carta de apresentação para V. Ex. Está ele muito descontente com Urquiza [...]. Dissuadido da conspiração, resolveu-se a seguir para o Chile, com escala pelo Rio de Janeiro. Eu o trouxe para aqui no Recife, e agora segue no Prince.

Como o Dr. Sarmiento acompanhou a Urquiza na sua campanha além do Paraná, pode instruir a V. Ex., e a S. M. o Imperador de muitas particularidades úteis, e pois rogo lhe que cultive as relações com o dito Dr., e o apresente mesmo a S.M. o Imperador, que estou certo gostará de o ouvir. Há no Dr. Sarmiento alguma cousa de poesia, mas dado esse desconto, e [ilegível] a importância que ele crê ter, há nele muito a aproveitar...

Sou De V. Exa.

[abreviaturas de tratamento]

Honório Hermeto Carneiro Leão.

Diante da documentação, por fim, é de se notar que, no decorrer dos oitocentos, o assunto literário interamericano se encontrou longe de estar separado das outras esferas do saber/poder, instâncias à época irreversivelmente capturadas pelo Estado, quer ele monárquico, quer ele republicano, restando assim imiscuído e positivado pelo espectro político, diplomático, econômico, jurídico e, às vezes, conforme visto acima, bélico. Tal fato interditaria a consideração e circulação social da espessura eminentemente poética acerca da formação do objeto literário interamericano naquele período.

Por tudo isso, cabe dizer que a questão da autonomia na interseção dos campos letrados argentino e brasileiro é abordada por ângulos díspares. Ora são buscadas as equivalências comparativas entre ambos os campos, com inclinação a reduzir a produção nacional (Norberto, Echeverría e Gutiérrez) ao estado de reformulação em que se enxerga o romantismo em terras americanas; ora se escreve (Sarmiento, Mármol, assim a correspondência entre Paulino Soares e Carneiro Leão) a modo de entender as 
debilidades institucionais e editorias mediante as quais não se chegava nunca a uma autonomia da poiésis interamericana em ambos os meios letrados, sendo a sua própria produção atingida pela impossibilidade de ser recebida entre nós sem coexistir com a intervenção de outros círculos do poder/saber, conforme apresentam as últimas cartas transcritas.

Em qualquer caso, o fato de se assimilar e discutir o tema é revelador de que a autonomização, embora não concretizada nos oitocentos, se encontrava em curso de historicidade, isto é, de compreensão no tempo. Optou-se, em qualquer um dos eventos analisados, pelo eixo de americanização da comparação, formulando assim os antecedentes constitutivos de um espaço literário por meio de uma perspectiva interamericanista que muitas vezes pretendeu a inserção transnacional antes mesmo da formação nacional.

O que se buscou mostrar com tudo isso foi o percurso de constituição do enunciado do perspectivismo interamericano como uma posição ao mesmo tempo ideológica e epistemológica ao comparatismo tradicional. No decurso do tempo, tal prática conduziria a um processo heterogêneo de autonomização da produção literária americana em relação à determinação do discurso político que, conforme vimos acima, era a esfera que exclusivamente assegurava a circulação pública - ou a sua interdição dos textos literários no contexto do romantismo na Argentina e no Brasil. Como vimos, a condição do exilio imposta ao grupo argentino pela ditadura de Rosas foi o imperativo para o revisionismo nacionalista e o encaminhamento - ainda que não premeditado para uma dinâmica intercontinental de fundamentação não essencialista, alcançando uma dimensão de extensão transnacional, assim criada na constituição do vínculo primordial entre dois ou mais meios literários americanos por meio da inserção cultural em lugar da ontologia da formação nacional que via de regra impôs uma submissão comparativa.

\section{Fontes}

\section{Documentos eletrônicos}

ECHEVERRÍA, E.; GUTIÉRREZ, J. M (s/d). Epistolario. Edición digital de Leonor Fleming para la Biblioteca Virtual del Instituto Cervantes. Disponível em: << http://www.cervantesvirtual.com/obra/epistolario-entre-esteban-echeverria-yjuan-maria-gutierrez-1840-1845/ >. Acesso em: 19 ago. 2019. A referência do epistolário impresso, no qual se baseia a versão de Fleming, é a seguinte: Raúl J. 
Moglia y Miguel O. García (eds.) (1979-1981). Archivo del doctor Juan María Gutiérrez. Epistolario, 2 tomos. Buenos Aires: Biblioteca de La Nación.

\section{Documentos de arquivo}

CARNEIRO LEÃO, H. H (1852). Cartas de Honório Hermeto Carneiro Leão Paraná, a Paulino José Soares de Sousa; comenta sobre a conversa que teve com José MÁRMOL acerca de enviar exemplares da obra "Amália" para ser vendida no Rio de Janeiro. Localização: 63,03,006 n055. Localização antiga: TM-22,22TM24,68. Local: Montevidéu. Data: 25/03/1852. Paginação: 4 doc. (16 p.). Série arquivística: Visconde do Uruguai.

SARMIENTO, D. F (1852). Carta de Domingo Faustino SARMIENTO a José Soares de Souza sobre a situação política argentina e o resultado das conferências que teve com o imperador brasileiro em Petrópolis. Localização: 63, 04, 001 n 015 ; Localização antiga: TM-23,1TM-22,10TM-24,30; Local: Rio de Janeiro; Data: 09-14/04/1852; Idioma: espanhol; Série arquivística: Visconde do Uruguai.

\section{Referências bibliográficas}

AMANTE, A. (2010). Poética y políticas del destierro. Argentinos en Brasil en la época de Rosas. Buenos Aires: FCE.

DINIZ, D (2013). Instinto(s) de transnacionalidade. Ensaio sobre a sociabilidade nos campos literários argentino e brasileiro (1840 | 1940). Trabalho de conclusão de residência em pesquisa PNAP-R. Rio de Janeiro: Fundação Biblioteca Nacional, 2017.

La cautiva. In: CROCE, M. (presentación y selección de textos). Para animarse a leer a Esteban Echeverría. Buenos Aires: Eudeba, p. 49-83.

GUTIÉRREZ, J. M (1846). América poética. Colección escogida de composiciones em versos escritas por americanos en el presente siglo. Parte Lírica. Valparaíso: Imprenta del Mercurio.

(1860). A Confederação dos Tamoyos, porma por Domingo Gonçalves de Magalhães. In: _. Apuntes biográficos de escritores, orados y hombres de estado de la Republica Arjentina. Buenos Aires: Imprenta de Mayo, p. 225-274.

MARMÓL, J (2010). Juventude progressista do Rio de Janeiro. In: Ostentor Brasileiro. Jornal literário e pictorial. Edição fac-similar (1845-1846). Rio de Janeiro: Fundação Biblioteca Nacional, p. 352-355-356-357.

MOREIRA, M. A (2013). Hermanos e irmãos: as relações literárias entre os românticos argentinos e brasileiros durante o romantismo. In: Teresa - Revista de Litratura Brasileira, no 12/13, São Paulo, p. 79-93.

(1997). Rio-Janeiro. Carta al Señor don Miguel Piñeiro Viajes. Edición crítica de Javier Fernández (coordinador). París, México, Buenos Aires, São Paulo, etc.: ALLCA XX, p. 56-74.

SOUSA SILVA, J. N (1844). Indagações sobre a literatura argentina. In: Minerva brasiliense. $\mathrm{N}^{\mathrm{o}}$ 10. Vol. 1. Rio de Janeiro, 15 de março, p. 294-301. 
WEINBERG, F (1961). La literatura argentina vista por un crítico brasileño en 1844. Rosário: Universidad Nacional del Litoral/Facultad de Filosofía y Letras.

Artigo recebido em 19 de agosto de 2019.

Aprovado em 27 de dezembro de 2019.

DOI: 10.12957/intellectus.2020.44649 